\title{
Community People's Preference of Hand Drawn Face Graph as a Health Informing Device
}

\author{
Masaki Moriyama, Shin-Ichi Matsubara, ${ }^{*}$ Hiroshi \\ SAIto and Kokichi Iwata \\ Department of Preventive Medicine and Health Promotion, \\ Nagasaki University School of Medicine, Nagasaki 852, \\ and *Department of Engineering, Faculty of Education, \\ Nagasaki University, Nagasaki 852
}

\begin{abstract}
Moriyama, M., Matsubara, S., Saito, H. and Iwata, K. Community People's Preference of Hand Drawn Face Graph as a Health Informing Device. Tohoku J. Exp. Med., 1990, 160 (1), 37-46_ Although the cartoon of a face is an effective device to visualize the image of numerical indices, its use is not popular among community health personnel. In the present study, we used the face graph as an aid for health informing and educating activities in the setting of a community health activity. For this purpose, we designed a special sheet to draw face by hand. By using this sheet, each person can draw his/her 'face' from one's laboratory data index under the guidance of additional lines. The acceptability of this hand drawn face was evaluated by 283 people aged 65 years and over at a health counseling session. For both men and women, a higher percentage preferred face ( $37 \%$ for men, $40 \%$ for women) over numeral ( $23 \%$ for men, $17 \%$ for women). The preference for the face graph was also observed at each of three age groups within each sex. The highest affinity to face $(64 \%)$ was observed for the 14 women who reported as cataract patients. communication; hand drawn face graph; community health; health information; health education
\end{abstract}

An increasing number of people take health checkups organized by community health interest groups in accordance with the aging of society (Health and Welfare Statistics Association 1989). Results of health checkups are usually obtained as numerical indices. These numerals are usually written down directly into the prescribed health information form. Community health personnel inform examinees of their health status by the use of these personal numerical forms. Most of aged examinees, however, cannot fully comprehend their own health status expressed in a numerical form. Community health personnel also report difficulty in explaining such numerical results,

The effectiveness of graphics as a tool for summarizing multiphasic data is now well established. Of the many multivariate methods developed for graphics, the most widely recognized is Chernoff's faces (Chernoff 1973; Gugel 1985). In

Received October 18, 1989; revision accepted for publication December 15, 1989. 
this method, each point in k-dimensional space, is represented by a cartoon of a face (face graph), whose features, such as length of nose and curvature of mouth, correspond to components of the point.

We intended to use graphics as a communicative aid for health informing and educating activities. Chernoff's face is of special interest since humans perceive the face as a gestalt and humans possess a special innate ability for visually processing faces (Gugel 1985). Intending to use the face as a device to communicate the major conclusion of health checkup to examinees in community health activities, we already developed a simple face drawing system for lap-top microcomputers (Matsubara and Moriyama 1989). This system is, however, not so comfortable for the aged people, who prefer person-to-person communication rather than the one-sided appraisal assisted by computer. In the present study, our goals are 1) to simplify the process of face drawing, 2) promote the communicative use of the face graph, and 3) to test the acceptability of the face graph in a setting of community health activity. For these purposes, a special sheet is offered to draw face by hand. Using this sheet, community people as well as the community health personnel can draw a face from a personal laboratory data, under the guidance of additional lines. The acceptability of this face graph was evaluated by the aged people at a health counseling session.

\section{Subjects and Methods}

Design of face graph

Intending to establish the criteria to describe a variety of facial expressions in experimental psychology, Schlosberg (1952) classified 72 pictures of male face using two rating scales: (1) pleasantness-unpleasantness, and (2) attention-rejection. This pleasantnessunpleasantness scale was later applied by Honda and Aida (1982) in designing a new face graph. We also adopted Schlosberg's first dimension and assigned three-valued positions to each of facial features. Fig. 1 shows our face graph using a maximum of seven features which vary. Three positions ( $\mathrm{a}, \mathrm{b}, \mathrm{c}$ ) of facial features were corresponded to 'pleasantness', 'intermediate' and 'unpleasantness', respectively (Table 1). These three positions were

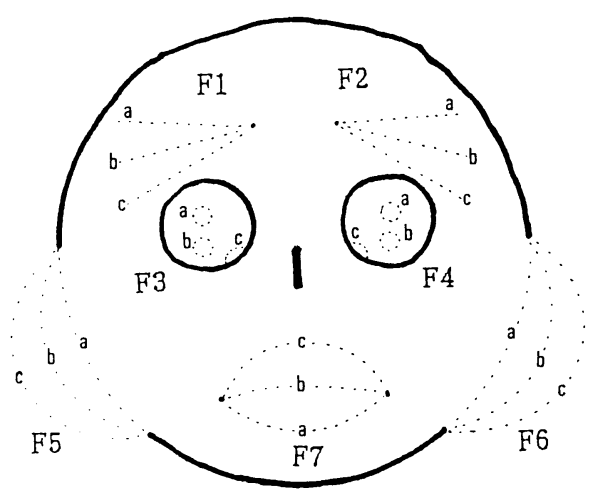

Fig. 1. Face pattern showing seven facial features. 
TABLE 1. Correspondence between feature positions, pleasantness-unpleasantness and normal-abnormal

\begin{tabular}{|c|c|c|c|c|}
\hline $\begin{array}{l}\text { Positions } \\
\text { of } \\
\text { features }\end{array}$ & & $\begin{array}{l}\text { Pleasantness- } \\
\text { unpleasantness } \\
\text { scale }\end{array}$ & & $\begin{array}{l}\text { Normal- } \\
\text { abnormal } \\
\text { scale }\end{array}$ \\
\hline a & $\Longleftrightarrow$ & Pleasant & $\Longleftrightarrow$ & Normal \\
\hline $\mathrm{b}$ & $\Longleftrightarrow$ & Intermediate & $\Longleftrightarrow$ & Borderline \\
\hline $\mathrm{c}$ & $\Longleftrightarrow$ & Unpleasant & $\Longleftrightarrow$ & Abnormal \\
\hline
\end{tabular}

TABLE 2. Facial features and judgements of laboratory variables

\begin{tabular}{llccc}
\hline \multirow{2}{*}{\multicolumn{1}{c}{ Facial features }} & \multicolumn{4}{c}{ Laboratory variables } \\
\cline { 2 - 5 } & \multicolumn{2}{c}{ Items } & a & Judgements \\
& & - & $\pm \sim+$ & c \\
\hline F1 Angle of right eyebrow & Urinary protein & - & $\pm \sim+$ & $+\sim$ \\
F2 Angle of left eyebrow & Urinary glucose & & & \\
F3 Position of right eyeball & (Not used) & & & \\
F4 Position of left eyeball & (Not used) & -19.9 & $20.0-24.9$ & $25.0+$ \\
F5 Curvature of right chin & Body mass index & -19.9 & $20.0-24.9$ & $25.0+$ \\
F6 Curvature of left chin & Body mass index & -139 & $140-159$ & $160+$ \\
F7 Curvature of mouth & Systolic blood pressure & & & \\
\hline
\end{tabular}

further described as corresponding to the three levels for the numerical indices as 'normal', 'borderline' and 'abnormal'. In applying this face to the actual data, five facial characteristics (F1, F2, F5, F6, F7) were selected to correspond to four laboratory variables (Table 2). The remaining two facial characteristics (F3, F4) were not used in the present study.

\section{Study population}

The face graph was used at a health counseling session in a town of Takashima, in March 1988. Takashima is a small island formerly highly industrialized by coal mining. In two years after the shut-down of coal mining in November 1986, the population decreased from 5491 to 1577. According to our former survey in February 1987 (Moriyama and Saito 1989), more than $70 \%$ of people aged 56 years and over expressed anxiety about their health status in the future. Only a small percentage of people, however, actually planned to participate in community based health checkups. Thus, the development of a practical way to provoke people's interest toward their own health promotion was the urgent necessity in this aged and depopulated community.

\section{Setting of study}

Of the population of 367 aged 65 years and over, 283 people $(77 \%)$ attended a community based health counseling session. At first, subjects were asked about their general health conditions and the use of hospital-based medical care during the preceding month. Subjects were, then, measured for their height, weight and blood pressures. Body mass index (BMI) was calculated by the following formulae: $\mathrm{BMI}=$ (weight in $\mathrm{kg}) /($ height in meter $)^{2}$. Secondly, chemical determinations of urine were completed by the dip-strips method for the detection of protein and glucose.

In the result informing session after the health checkup, we informed examinees of the 
TABle 3. Numerical form of personal health checkup results

\begin{tabular}{|c|c|c|c|c|c|}
\hline \multirow{2}{*}{ Laboratory variables } & \multirow{2}{*}{$\begin{array}{l}\text { YOUR } \\
\text { VALUE }\end{array}$} & \multicolumn{3}{|c|}{ Judgements } & \multirow{2}{*}{$\begin{array}{l}\text { Major } \\
\text { suspected } \\
\text { disease }\end{array}$} \\
\hline & & Normal & Borderline & Abnormal & \\
\hline Urinary protein & ) & - & $\pm \sim+$ & H & Renal disease \\
\hline Urinary glucose & ( & - & $\pm \sim+$ & $H \sim$ & Diabetes \\
\hline Body mass index & ) & -19.9 & $20.0-24.9$ & $25.0+$ & Obesity \\
\hline Systolic blood pressure & ( & -139 & $140-159$ & $160+$ & Hypertension \\
\hline
\end{tabular}

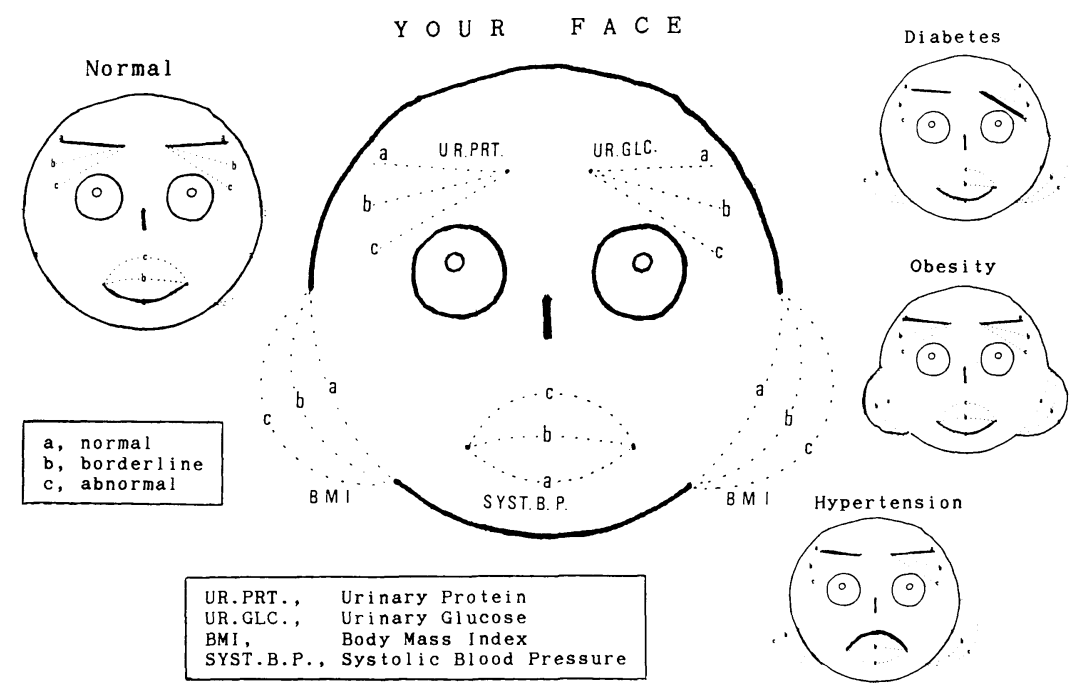

Fig. 2. Facial form of personal health checkup results.

results from the tests using the numerical form (Table 3) and facial form (Fig. 2). When two forms were completed, each examinee was instructed to select the preferable one (numerical or facial form). Details of instructions are given in Table 4.

\section{Results}

Profile of general results

A total of 283 residents participated in the study. The general characteristics of participants are shown in Table 5. Sixty three percent of participants reported the use of hospital-based medical care during the preceding month. The major self-reported health problems were hypertension $(29 \%)$, gastric problems $(11 \%)$, heart problems $(11 \%)$ and cataract $(5 \%)$.

Response to face graph

When age groups are combined, a higher percentage of men preferred face $(37 \%)$ than numeral $(23 \%)$, and face/numeral ratio was 1.56 (Table 6). Women were more likely to prefer face $(40 \%)$ than numeral $(17 \%)$, and face/numeral ratio 
TABLE 4. Sequence of verbal and non-verbal instructions given by the examiner during the result informing session

\begin{tabular}{|c|c|}
\hline Verbal instruction & Non-verbal instruction \\
\hline $\begin{array}{l}\text { We are doing this study to improve the health inform- } \\
\text { ing form used in the health checkup. Please listen } \\
\text { carefully and follow my instruction. }\end{array}$ & $\begin{array}{l}\text { Extends the two forms in front of } \\
\text { the examinee. }\end{array}$ \\
\hline $\begin{array}{l}\text { At first, I will explain to you the result of today's } \\
\text { health checkup by the use of these two forms, numer- } \\
\text { ical and facial. Next, I will ask your preference of } \\
\text { these two forms. } \\
\text { (Pause) }\end{array}$ & Point each of the form. \\
\hline $\begin{array}{l}\text { This is the numerical form. By using this form, I will } \\
\text { explain to you the results in numerals. }\end{array}$ & $\begin{array}{l}\text { Present the numerical form. Orally } \\
\text { announce the numerical value and } \\
\text { write down the value in the paren- } \\
\text { thesis. }\end{array}$ \\
\hline $\begin{array}{l}\text { Each of your value corresponds to one of these three } \\
\text { judgments; normal, borderline and abnormal. } \\
\text { (Pause) }\end{array}$ & $\begin{array}{l}\text { Mark one of three judgments for each } \\
\text { value. }\end{array}$ \\
\hline $\begin{array}{l}\text { This is the facial form. I will explain your results by } \\
\text { drawing one of these three dotted lines. Three of } \\
\text { judgments (such as normal, borderline and abnor- } \\
\text { mal) correspond to three facial features (such as } \\
\text { pleasantness, intermediate and unpleasantness). } \\
\text { (Pause) }\end{array}$ & $\begin{array}{l}\text { Present the facial form. Orally an- } \\
\text { nouce the numerical value. } \\
\text { Draw one of three dotted lines on the } \\
\text { facial form. }\end{array}$ \\
\hline $\begin{array}{l}\text { Now, I already explained you the resulted health status } \\
\text { by the use of these two forms. In the coming health } \\
\text { checkup, we are planning to use either form which } \\
\text { you prefer. Now, which form do you prefer? } \\
\text { Please select one of the following three answers; 1) } \\
\text { numerical form, 2) facial form, 3) difficult to select. } \\
\text { Please decide your mind considering the understan- } \\
\text { dability and acceptability of these forms. }\end{array}$ & \\
\hline
\end{tabular}

was 2.34. Forty percent of the men and $42 \%$ of the women did not select a preference for either of the forms. The preference of face was also observed at each of the three age level groups for each sex. The highest face/numeral ratio was observed at 80-89 years of age in each sex group.

\section{Health conditions and preference of face}

By the use of self-reported health conditions, subjects were classified into 'hospital use' group and 'hospital not use' group. In 'hospital use' group, four groups were further identified according to the major health problems. Face/ numeral ratio was compared among five groups of various health conditions for each sex (Table 7). In the group of men who reported to have either 'hypertension' or 'heart problems', equal number of participants preferred numeral and/or face, and the face/numeral ratio was 1.0. In the remaining two groups of men, and in all of the five groups of women, face/numeral ratio was larger than 1.0. Of 
TABLE 5. General characteristics

\begin{tabular}{lrc}
\hline & $n$ & $\%$ \\
\hline Sex & 115 & 41 \\
Men & 168 & 59 \\
Women & & \\
Age (years) & 87 & 31 \\
$60-69$ & 155 & 55 \\
$70-79$ & 41 & 14 \\
$80-89$ & & \\
Use of hospitals & 180 & 64 \\
Yes & 97 & 34 \\
No & & \\
Health problems & 83 & 29 \\
Hypertension & 32 & 11 \\
Gastric problem & 31 & 11 \\
Heart problem & 15 & 5 \\
Cataract & 283 & 100 \\
Total &
\end{tabular}

$n$, number of subjects; $\%$, percent to total.

Table 6. Preferred type of information by sex and age

\begin{tabular}{|c|c|c|c|c|c|c|c|c|c|c|}
\hline \multirow{3}{*}{ Age } & \multirow{2}{*}{\multicolumn{2}{|c|}{ Total }} & \multicolumn{6}{|c|}{ Preferred type of information } & \multirow{2}{*}{\multicolumn{2}{|c|}{ Face/numeral ratio }} \\
\hline & & & \multicolumn{2}{|c|}{ None } & \multicolumn{2}{|c|}{ Numeral } & \multicolumn{2}{|c|}{ Face } & & \\
\hline & $n$ & $\%$ & $n$ & $\%$ & $n$ & $\%$ & $n$ & $\%$ & Ratio & $95 \%$ limit \\
\hline \multicolumn{11}{|l|}{ Men } \\
\hline All ages & 115 & 100 & 46 & 40 & 27 & 23 & 42 & 37 & 1.56 & $0.75-3.29$ \\
\hline 60-69 years & 33 & 100 & 14 & 42 & 8 & 24 & 11 & 33 & 1.38 & $0.32-5.91$ \\
\hline $70-79$ years & 71 & 100 & 28 & 39 & 17 & 24 & 26 & 37 & 1.53 & $0.60-3.92$ \\
\hline $80-89$ years & 11 & 100 & 4 & 36 & 2 & 18 & 5 & 45 & 2.50 & $0.19-37.77$ \\
\hline \multicolumn{11}{|l|}{ Women } \\
\hline All ages & 168 & 100 & 71 & 42 & 29 & 17 & 68 & 40 & 2.34 & $1.25-4.41$ \\
\hline $60-69$ years & 54 & 100 & 19 & 35 & 11 & 20 & 24 & 44 & 2.18 & $0.75-6.46$ \\
\hline $70-79$ years & 84 & 100 & 34 & 40 & 15 & 18 & 35 & 42 & 2.33 & $0.95-5.77$ \\
\hline 80-89 years & 30 & 100 & 18 & 60 & 3 & 10 & 9 & 30 & 3.00 & $0.40-24.61$ \\
\hline
\end{tabular}

$n$, number of subjects ; $\%$, percent to row total. 
TABLE 7. Health conditions and preferred type of information

\begin{tabular}{|c|c|c|c|c|c|c|c|c|c|c|c|}
\hline & \multicolumn{2}{|c|}{ Health condition } & \multirow{2}{*}{\multicolumn{2}{|c|}{ Total }} & \multicolumn{6}{|c|}{ Preferred type of information } & \multirow{3}{*}{$\begin{array}{c}\text { Face/ } \\
\text { numeral } \\
\text { ratio }\end{array}$} \\
\hline & \multirow{2}{*}{$\begin{array}{c}\text { Hospital } \\
\text { use }\end{array}$} & \multirow{2}{*}{$\begin{array}{l}\text { Health } \\
\text { problem }\end{array}$} & & & \multicolumn{2}{|c|}{ None } & \multicolumn{2}{|c|}{ Numeral } & \multicolumn{2}{|c|}{ Face } & \\
\hline & & & $n$ & $\%$ & $n$ & $\%$ & $n$ & $\%$ & $n$ & $\%$ & \\
\hline \multirow[t]{6}{*}{ Men } & No & - & 50 & 100 & 24 & 48 & 9 & 18 & 17 & 34 & 1.89 \\
\hline & Yes & Hypertension & 32 & 100 & 14 & 44 & 9 & 28 & 9 & 28 & 1.00 \\
\hline & & Gastric problem & 12 & 100 & 5 & 42 & 2 & 17 & 5 & 42 & 2.50 \\
\hline & & Heart problem & 13 & 100 & 5 & 38 & 4 & 31 & 4 & 31 & 1.00 \\
\hline & & Cataract & 1 & 100 & 0 & 0 & 0 & 0 & 1 & 100 & - \\
\hline & & Total & 65 & 100 & 22 & 34 & 18 & 28 & 25 & 39 & 1.39 \\
\hline \multirow[t]{6}{*}{ Women } & No & - & 53 & 100 & 20 & 38 & 12 & 23 & 21 & 40 & 1.75 \\
\hline & Yes & Hypertension & 51 & 100 & 25 & 49 & 6 & 12 & 20 & 39 & 3.33 \\
\hline & & Gastric problem & 20 & 100 & 8 & 40 & 5 & 25 & 7 & 35 & 1.40 \\
\hline & & Heart problem & 18 & 100 & 11 & 61 & 2 & 11 & 5 & 28 & 2.50 \\
\hline & & Cataract & 14 & 100 & 4 & 29 & 1 & 7 & 9 & 64 & $9.00^{\mathrm{a}}$ \\
\hline & & Total & 115 & 100 & 51 & 44 & 17 & 15 & 47 & 41 & 2.76 \\
\hline
\end{tabular}

$n$, number of subjects; $\%$, percent to row total.

aStatistical significance was suggested $(\mathrm{p}=0.11)$ against control group (No hospital use) by Fisher's exact test.

the 14 women who reported to have a cataract condition, nine $(64 \%)$ preferred face, and the face/numeral ratio (9.0) was the highest among all groups. Statistical significance was suggested $(\mathrm{p}=0.11)$ against control group (no hospital use) by Fisher's exact test.

\section{Discussions}

\section{Possibility of face graph as a communicative device}

Chernoff (1973) indicated the following four areas as the use of graphic representations in general : such that (1) enhancing the user's ability to detect and comprehend important phenomena, (2) serving as a mnemonic device for remembering major conclusions, (3) communicating major conclusions to others, and (4) providing the facility for doing relatively accurate calculations and predictions informally. With special reference to the use of face as a hopeful graphic technique in the future, however, Chernoff restricted its use to the first two types (1 and 2).

After Chernoff, the type 1 (detection and comprehension) and type 2 (remembering) use of face graph was applied to a variety of multivariate data in health sciences : ranging from biochemical data (Robertson et al. 1980 ; Honda and Aida 1982 ; Kondo and Mori 1987) to socio-geographical data (Watson 1980). Until recently, the type 3 (communication) and type 4 (calculation and prediction) use has not been considered. In this study, we intended to use face as a communica- 
tive device, which corresponds to type 3 use of Chernoff. Community people's preference of face graph revealed in this study seems to be a prerequisite condition for its further communicative use in the future.

\section{Improvement of face graph}

In this study, the following two stages were followed to develop the face graph: (1) determining seven as the maximum number of facial features (Fig. 1), (2) setting feature-numeric correspondence in Table 2 . To develop further the ability of face graph as a communication device, each of above two processes should be reviewed and refined.

Maximum number of facial features. Chernoff's face (1973) was constructed using 18 variables. However, no clear-cut criteria has been offered for the maximum number of features expressed in a face. For example, Goldstein et al. (1971) studied the normal perceptual processes of human face using 34 features. In contrast, Honda and Aida (1982) used seven features to illustrate medical diagnosis. We intended to simplify the process of face drawing, and adopted seven features with three-valued positions. Even in our simplified setting, however, maximum of $2187\left(3^{7}\right)$ variations can be displayed. Practically, the maximum number of facial features should be chosen according to the needs of the supposed users.

Feature-numeric correspondence. To avoid the misunderstanding of message expressed in a face, the correspondence between facial expression and laboratory value should be easy to imagine for the examinee. Since face is perceived as a gestalt, the balance of facial features are important. In fact, Chernoff adopted symmetrical positions for each corresponding features. Therefore, we corresponded body mass index to both sides of cheek. However, as the total number of our facial feature is limited to seven, retention of complete symmetry causes the reduction of corresponding parameters to three. Thus, we did not seek the complete symmetry and corresponded two different urinary measurements to the right and left eyebrows, respectively. At present, we are not sure that this asymmetry causes some unpleasant feeling to the examinee. Up until the early 1980's, most of researchers following Chernoff used symmetrical face graphs. Flury and Riedwyl (1981), however, developed a new asymmetrical face technique, and the resulting face diagrams are reported to be far more realistic than Chernoff's (Gugel 1985). Thus, in the actual setting of the balance of facial features, the moderate degree of asymmetry might be permitted. In the actual use of our face drawing sheet under the different socio-cultural settings, the community health personnel should seek the most appropriate feature-numeric correspondence in a given situation.

\section{Suspected reason of preference of information}

At the result informing session, we stressed the importance of understan- 
dability and acceptability as the major concern to select the preferable form (Table 4). For most of the examinee, however, the actual reasons of preference seem to be rather emotional than rational. Although we did not directly ask the reason of preference, some of examinees voluntarily revealed their feelings accompanying their decisions. For example, those who preferred face tended to reveal intimacy and interest to face. Those who preferred numerals tended to reveal their reliability and acquaintance to numerals. Therefore, the preference of face and/or numeral does not necessarily mean that the preferred one is more understandable in comparison to the not-preferred one. To clarify further the understandability of face, testing situations should be refined in the coming study.

Those who preferred neither numerals nor face did not further comment on their choice. Because of the age dependent increase of none preference ratio in women, this 'none preference' might imply the difficulty in understanding the information regardless of the type (numerical and/or facial).

\section{Health condition and preference of information}

To study the relationship between the health condition and the preference of information, we compared face/numeral ratio among groups of various health conditions. Hence, most of clinical decisions made during the natural history of a given disease depend on some specific numerical indices, patients are expected to have affinity and interest toward specific numerals. In fact, several hypertensive patients attributed their preference of numerals to their keen interests to blood pressure values caused by the repeated measurements throughout the course of the disease. However, the face/numeral ratio of the people with hypertension, as a group, was not significantly larger than the control group.

In the group of cataract, all people complained the difficulty of vision, and highest percentage of people preferred face. The face graph was supposed to be more visible than numerals for the cataract patients. In the coming study, both of 'affinity to specific numerals' and 'visibility' should be evaluated as the independent factors related to the preference of information.

\section{Communicative use of face graph in the setting of a community health activity}

Introduction of a facial cartoon into a community health activity was an entirely new experience not only for the community people but for ourselves. Because in Japan, cartoons have been recognized as the informal way of expression, and they have never been actually used in the clinical and/or community health settings on the personal basis. However, hand-drawn face graph relieved the tense atmosphere of the informing session, and both of community people and our research staffs welcomed the face graph. We have not yet evaluated the quantitative change of person-to-person communication caused by our handdrawn face graph. Judging from the subjective feelings shared by our staffs, however, there is a good possibility that both of the hand drawing process and the 
resulted face graph facilitated the two way communication between examiners and examinees. Therefore, the drawing process should not easily be replaced by a computer. To promote further the communicative use of the face graph, the changing amount of communication between examiners and examinees should be evaluated in the coming study.

\section{Acknowledgments}

We thank Dr. Takahiro Sato, President, NEC Technical College, NEC Corporation and Dr. Delwyn L. Harnisch, Professor, Institute for Child Behavior and Development, University of Illinois at Urbana-Champaign, for their valuable suggestions. This study was partly supported by a Grant-in-Aid (No. 01570318) from the Ministry of Education, Science and Culture, Japan.

\section{References}

1) Chernoff, H. (1973) The use of faces to represent points in k-dimensional space graphically. J. Am. Statist. Ass., 68, 361-368.

2) Flury, B. \& Riedwyl, H. (1981) Graphical representation of multivariate data by means of asymmetrical faces. J. Am. Statist. Ass., 76, 757-765.

3) Goldstein, A.J., Harmon, L.D. \& Lesk, A.B. (1971) Identification of human faces. Proc. IEEE, 59, 748-760.

4) Gugel, H.W. (1985) Graphical profiles of multivariate data. In: Research Publication GMR-4896, General Motors Research Laboratories, Warren, Michigan, pp. 2-42.

5) Health and Welfare Statistics Association (1989) Health for the adult. In : Trend of National Health, Health and Welfare Statistics Association, Tokyo, pp. 114-121. (Japanese)

6) Honda, N. \& Aida, S. (1982) Analysis of multivariate medical data by face method. Pattern Recognition, 15, 231-242.

7) Kondo, H. \& Mori, H. (1987) A computer system applying the face method to represent multiphasic tests. Med. Inf., 12, 217-222.

8) Matsubara, S. \& Moriyama, M. (1989) Computer assisted health informing system. IEICE Technical Report, 88(457), 25-28. (Japanese)

9) Moriyama, M. \& Saito, H. (1989) Health status of a community experiencing rapid population decrease - results of a survey of Takashima following the shut down of coal mine. Jpn. J. Publ. Hlth., 36, 8-22. (in Japanese with English abstract)

10) Robertson, E.A., Van Steirteghem, A.C., Byrkit, J.E. \& Young, D.S. (1980) Biochemical individuality and the recognition of personal profiles with a computer. Clin. Chem., 26, 30-36.

11) Schlosberg, H. (1952) The description of facial expressions in terms of two dimensions. J. Exp. Psychol., 44, 229-237.

12) Watson, C.J. (1980) An empirical model of physician practice location decisions. Comput. Biomed. Res., 13, 363-381. 